\title{
O chapéu do Boto-Homem: uma breve análise sobre a diversidade sexual e gênero a partir das relações entre humanos, não-humanos e coisas na Amazônia
}

Resumo: Propõe-se aqui apresentar uma reflexão sobre as relações entre as experiências da diversidade sexual e de gênero, as corporalidades, a cultura material e as paisagens no interior da Amazônia, a partir de uma pesquisa etnográfica em andamento. Objetiva-se principalmente discorrer sobre os usos e significados do vestuário como um agente importante na constituição de ontologias, formas de conhecimentos e subjetividades. Num primeiro momento, trata-se de discorrer sobre a indumentária (particularmente, o chapéu do mitológico boto-homem) como um agente importante na constituição do corpo e da paisagem na Vila de Alter do Chão, no Pará, por meio de um conhecimento ontológico e pela descolonização do pensamento moderno dos estudos de sexualidade e gênero no Brasil. Em seguida, refletir-se-á sobre a "agentividade", o "encanto tecnológico" e os aspectos mais sensuais dos usos e desusos daquela indumentária por turistas e nativos em Alter do Chão. Assim, pretende-se apresentar outros modos de pensar um mundo no qual corpos, paisagens e coisas assumem relações de comunicação, consciência, intencionalidade e agência.

Palavras-chave: Sexualidade; corpo; cultura material; ontologia; Amazônia.

${ }^{1}$ Atualmente é doutorando pelo Programa de Pós-Graduação em Antropologia da Universidade Federal do Pará - bolsista CAPEs. Possui mestrado pelo mesmo programa (2020) e graduação em Antropologia pela Universidade Federal do Oeste do Pará (2018). 


\title{
The hat of the Boto-Man: a brief analysis of sexual and gender diversity based on the relations between humans, non-humans and things in the Amazon Basin
}

\begin{abstract}
I propose here to present a reflection on the relationships between the experiences of sexual and gender diversity, corporalities, material culture and landscapes in the countryside of the Amazon Basin, from ethnographic research in progress. The main objective is to discuss the uses and meanings of clothing as an important agent in the constitution of ontologies, forms of knowledge and subjectivities. At first, I will discuss the clothing (particularly, the hat of the mythological boto-man) as an important agent in the constitution of the body and the landscape in the village of Alter do Chão, in Pará, through an ontological knowledge and by decolonizing the modern thought of sexuality and gender studies in Brazil. Then, I will reflect on the "agentivity", the "enchantment of technology", and the more sensual aspects of the uses and disuses of that clothing by tourists and natives in Alter do Chão. Thus, I intend to present other ways of thinking about a world in which bodies, landscapes, and things assume relations of communication, consciousness, intentionality, and agency.
\end{abstract}

Keywords: Sexuality; body; material culture; ontology; Amazon.

\section{El sombrero del Boto-Hombre: un breve análisis sobre la diversidad sexual y de género basado en las relaciones entre humanos, no humanos y cosas en la Amazonía}

\begin{abstract}
Resumen: El propósito de este artículo es presentar una reflexión sobre las relaciones entre las experiencias de la diversidad sexual y de género, las corporalidades, la cultura material y los paisajes en el interior de la Amazonía a partir de una investigación etnográfica en curso. El objetivo principal es discutir los usos y significados de la ropa como agente importante en la constitución de ontologías, formas de conocimiento y subjetividades. En un primer momento, trataré de la ropa (particularmente, del sombrero del boto-hombre) como un agente importante en la constitución del cuerpo y del paisaje en la aldea de Alter do Chão, Pará, a través de un conocimiento ontológico y la descolonización del pensamiento moderno de los estudios de sexualidad y género en Brasil. Luego, trataré de reflexionar sobre la "agentividad", el "encantamiento tecnológico" y los aspectos más sensuales de los usos y desusos del sombrero por parte de turistas y nativos en Alter do Chão. Así, pretendo presentar otras formas de pensar un mundo en el cual los cuerpos, los paisajes y las cosas asumen relaciones de comunicación, conciencia, intencionalidad y agencia.
\end{abstract}

Palabras clave: Sexualidade; cuerpo; cultura material; ontologia; Amazonia. 
$\mathrm{N}$ ascer, crescer e viver na Amazônia é coexistir com tabus, encantarias, mitos, alusões, curiosidades e imaginários. Entre idas e vindas do rio Tapajós ${ }^{2}$, dos igarapés, das comunidades do planalto, das comunidades ribeirinhas e das aldeias indígenas, pude perceber o quanto ser amazônida 3 representa para mim. As águas do rio Tapajós e dos igarapés sempre estiveram presentes em minha realidade. $O$ bairro onde eu nasci e cresci fazia fronteira com as águas do rio, ou seja, nós transitávamos na terra para água e da água para a terra como se fossemos anfíbios nos momentos de sociabilidade4. Formado por migrantes oriundos do Estado do Ceará, o bairro foi crescendo e se tornando um "gueto de Arigó5". Com adição de elementos nordestinos e nortistas, a Vila Arigó que está situada no bairro da Prainha, como é conhecida atualmente, é convidativa para o lazer. A sua localização encontra-se às margens do rio Tapajós, elemento principal para que as pessoas possam desfrutar do bairro. $\mathrm{O}$ rio e as experiências do não-antropólogo ${ }^{6}$ naquele momento são elementos fundamentais para compreender a paisagem e a diversidade sexual e de gênero a partir de suas experiências7 e presença nas paisagens, assim como a sua relação com as encantarias aquáticas e as indumentárias a elas relacionadas.

O lugar onde eu vivi durante a infância e adolescência traz lembranças incríveis. As ruas eram de chão batido e não tinham saneamento básico, e tampouco, asfalto. Isso não nos impedia de usá-las para construir um imaginário singular de um espaço que supria as necessidades do bem viver das crianças e dos adolescentes (eu) que ali residiam. Sem estrutura adequada para os nossos esportes e brincadeiras - pira pega, esconde-esconde, futebol, mata no meio, sete pecados entre outros - cria-se a sociabilidade entre os brincantes e as paisagens: as matas e o rio Tapajós. A realização do lazer nessas paisagens, tinha como praticantes crianças e adolescentes entre oito até treze anos de idade. Assim, a minha experiência sempre se mantinha em interação com as paisagens. $O$ esconde-esconde, por exemplo, consecutivamente acontecia em matas semife-

2 O Rio Tapajós nasce no Estado do Mato Grosso, é formado pela confluência do rio Teles Pires com o rio Juruena e banha boa parte do Estado do Pará. A sua bacia está distribuída pelos Estados do MT, PA, RO e AM. Quando combinado com o rio Juruena, o Tapajós tem aproximadamente $1900 \mathrm{~km}$ de comprimento. Esse rio faz parte do cenário turístico conhecido como "encontro das águas" com o Rio Amazonas bem em frente à cidade de Santarém (ALVES, 2012).

$3 \mathrm{O}$ ser, enquanto parte de uma proposta filosófica, é fazer parte de algo, de ter presença no mundo por meio do manuseio, do uso e do contato com o tempo, espaço e objeto. Assim, tudo o que precisamos e transformamos em experiências no mundo é resultado do que assumimos dentro dele (HEIDEGGER, 1995). Logo, o ser amazônida origina um modo de ocupação através da nossa experiência e presença no mundo, assim como a nossa existência através do tempo, espaço e objeto.

4 Sociabilidade é o conceito usado por Simmel para descrever como os indivíduos estabelecem suas necessidades e prazeres, e a partir deles, satisfazem seus interesses por meio da interação "toda essas formas de sociação são acompanhadas por um sentimento e por uma satisfação de estar justamente socializado, pelo valor da sociedade enquanto tal" (SIMMEL, 2006: 64).

5 A palavra "Arigó” é a designação de uma ave de arribação, migrante. Significa aquele que vem e não volta. Sobre o tema, ver: Jessie Jane Vieira de Souza, 1989. Arigó o pássaro que veio de longe. In: CENTRO DE MEMÓRIA SINDICAL. Coleção Trabalhadores em Luta, n.1. Rio de Janeiro.

${ }^{6}$ Não antropólogo e o antropólogo são dois momentos da minha vida. O primeiro é sobre as minhas experiências de quando era criança e adolescente no interior do Pará. A segunda é sobre a minha fase adulta e acadêmica retornando para a minha cidade natal para realizar a pesquisa de campo.

7 "Experiência que pode ser a de um indivíduo, de um grupo, de toda uma sociedade; experiência que pode dizer respeito às relações com o cosmo, com a natureza, consigo mesmo, como o grupo" (GOLDMAN, 2006: 167). Para Alfred Schutz (1970), a experiência faz parte do mundo da vida em que toda a esfera da experiência está contida nas relações cotidianas, direções e ações através das quais os indivíduos lidam com seus interesses e negócios, manipulando objetos, tratando com pessoas, concebendo e realizando planos. Já para Avtar Brah (2006), é um processo de significação para a constituição daquilo que compreendemos como "realidade". É importante assinalar que esse conceito não se trata de uma diretriz da "verdade", mas como uma prática em atribuir sentidos, tanto simbólicos como narrativos (memória). 
chadas como as mangueiras (Mangifera indica), castanholeiras (Terminalia catappa), jambeiros (Syzygium malaccense), entre várias outras espécies de árvores que são componentes das paisagens, tornando-as os melhores esconderijos. As matas descritas também estavam próximas do rio, e, nessa paisagem, pude pela primeira vez presenciar os corpos.

Os corpos não eram somente dos meus amigos e amigas, mas sim, dos marinheiros, pescadores (principalmente) e dos ribeirinhos que atracavam suas embarcações de pequenos, médios e grandes portes próximos à margem do rio Tapajós. No momento da ação de se esconder, o meu lugar preferido era o rio. Este último me proporcionava duas experiências naquela época. A primeira era o lugar perfeito para se observar os corpos. Eles estavam se movendo o tempo todo, seja para recolher a malhadeira, seja para se banhar, seja para fazer as necessidades fisiológicas etc. Os corpos, por estarem em interação com a água, sempre se encontravam molhados, mas sempre coberto, por um chapéu de palha. Os usos de objetos para cobri-los eram poucos, apenas um short ou somente uma cueca e o chapéu de palha. Essa é a primeira experiência com os corpos desejantes que se mantêm em constante contato com a água, corpos que no imaginário amazônico carregam uma simbologia erótica, no que tange às encantarias (como o mito do boto), principalmente ao uso do chapéu (do botohomem). Já a segunda experiência, trata-se de um toque ao corpo, começo a partir desse toque a conhecer o próprio corpo que habitava aquele rio. A sensação que eu recebia no contato com a água foi um exercício de manifestação do desejo. Nesse sentido, a experiência e a presença, tanto do não antropólogo naquele momento, como daqueles que eram observados ${ }^{8}$, são aprendizados que alinhavavam um outro modo de perceber as paisagens e o uso das coisas (indumentárias) a partir das encantarias, da constituição dos corpos e da sensorialidade na Amazônia.

A cultura material, principalmente a indumentária presente na encantaria 9 do boto, revela-nos um universo complexo de sistemas de significados e de relações simbólicas, assim como outras formas e regimes de percepções do mundo (ser/estar) que vão além de representações, signos ou símbolos (MILLER, 1954). As ontologias amazônicas, por exemplo, a encantaria do boto-homem, são importantes aliados nas observações de outras realidades. Ou melhor, de outros mundos e formas de existências de humanos, espíritos (encantados), plantas, animais... que fazem partes ou compõem um conjunto fundamental de entendimento sobre como o mundo é (ALBERTI, 2016). O meu objetivo é pensar a indumentária (como o chapéu do boto) como um agente importante na constituição do corpo e da paisagem na Vila de Alter do Chão, no Pará, por meio de um conhecimento ontológico e pala descolonização do pensamento moderno (LATOUR, 1994), dos estudos de sexualidade e gênero no Brasil.

\section{Entre o profano e o religioso: as marcas da festividade do Çairé}

O chapéu do boto está presente em vários enredos das cosmologias indíge-

\footnotetext{
8 Trata-se de uma ação. O observar não está sendo usado enquanto um aporte metodológico do fazer etnográfico, e sim, uma simples ação do olhar.

9 A encantaria e/ou encantado são categorias vernáculas usadas para descrever as relações entre os espíritos que habitam a floresta, a terra, o rio, o igarapé e igapó com os interlocutores presentes nessas paisagens. Os encantados, como são apresentados, são espíritos corporificados em formas humanas. Esses corpos são relatados durante a interação entre os encantados, as paisagens e os interlocutores, não necessariamente nessa ordem, pois elas podem partir de qualquer ponto desse intercurso de interações. Em relação a este artigo, me atentarei ao encantado (boto-homem). Em suma, os encantados fazem parte de um jogo de perspectivas (MAUÉS, 1990).
} 
nas e ribeirinhas, assim como no festival do Çairé. Trata-se de uma indumentária introduzida nas festividades locais, assim como no lazer entre banhistas e turistas que frequentam a Vila. Dentre os festivais que acontecem em Alter do Chão, destacam-se dois: o Festival Borari que ocorre durante o mês de julho, e o Festival do Çairé ${ }^{10}$ que acontece no mês de setembro. Ambos são celebrados durante a vazante do rio Tapajós (verão amazônico) que propicia o surgimento de praias de águas doces e cristalinas. O primeiro festival, segundo o site da portaria de turismo do Estado do Pará, é um evento organizado pela associação indígena Borari. A festividade celebra os costumes, tradições e práticas indígenas através das apresentações coreografadas e das alegorias de pequenos portes que trazem elementos das cosmologias indígenas e dos cânticos nativos dos indígenas Borari. Já o segundo festival é um evento que celebra a disputa entre duas agremiações que representam os dois botos da Amazônia: o Boto Tucuxi (Sotalia fluviatilis) e o Boto-Cor-de-Rosa (Inia geoffrensis). As disputas coreografadas por ambas as agremiações representadas pelos botos são carregadas de alegorias que remetem ao imaginário sobre a Amazônia, as cosmologias indígenas e ribeirinhas, as encantarias, a(s) sexualidade(s) e sobre o processo de sacralização do ritual ${ }^{11}$. É nesse contexto que me introduzo na Vila de Alter do Chão entre os anos de 2018 e 2019 nos meses de setembro (Verão Amazônico) e dezembro (Inverno Amazônico) ${ }^{12}$.

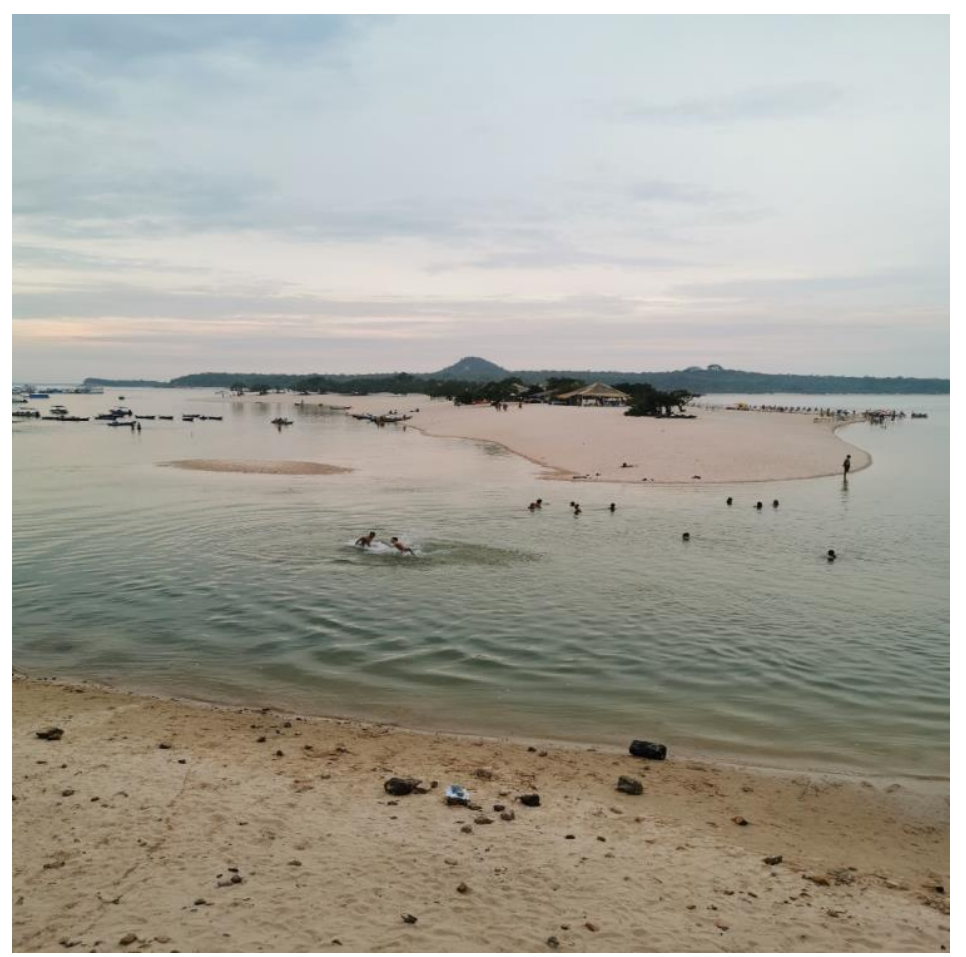

Figura 1. Ilha do Amor em época da vazante. Praia principal da vila de Alter do Chão. Foto: Igor Erick

\footnotetext{
${ }^{10}$ Há uma disputa entre os literários, administração pública, populares e indígenas sobre o uso correto do termo "Çairé" para designar o ritual que ocorre em Alter do Chão. O uso da grafia já foi apresentado de várias maneiras entre cronistas, jesuítas e literários. O debate não está no termo em si, mas na escolha entre as iniciais "S" e "C". Ao longo dos séculos a grafia foi sendo restruturada e ressignificada a partir de seus usos/desusos. Em Alter do Chão e na cidade de Santarém o termo se transformou em assunto nos debates do dia a dia na vila e na cidade. A prefeitura em 2014 postou em suas redes sociais e durante a promoção do festival o uso do termo com a inicial "S" a pretexto da adequação às normas da língua portuguesa, que não admitem a escrita de palavras iniciadas com a letra "Ç" (CARVALHO, 2016). Já os populares, principalmente na cidade de Santarém, compartilhavam do mesmo argumento que a prefeitura. Já os moradores indígenas e ribeirinhos da Vila de Alter do Chão, preferiam a escrita com "Ç". A justifica se dava ao resgate da palavra dita e escrita na língua nheengatu (variante do tupi) dos indígenas Borari durante a colonização da região.

${ }^{11}$ Sobre o festival do Çairé, ver Carvalho (2016).
}

12 Ver a dissertação de Mestrado por mim produzida (ERICK, 2020). 
A festividade do Çairé foi datada e narrada por cronistas e jesuítas como sendo um ritual indígena dos Borari que habitavam a região durante o século XVII (e habitam até hoje). Entretanto, a festa do Çairé é palco de diferentes concepções e narrativas fundacionais, dentre elas, a introdução de elementos cristãos e a preparação da festa para recepcionar os colonizadores portugueses. Hoje, o festival gira em torno de duas concepções: a festa religiosa e a festa profana (ou Festival Folclórico dos Botos). A festa religiosa atrai olhares curiosos de muitos turistas internacionais, nacionais e regionais. Alguns desses olhares se referem à "tradicionalidade do ritual", regada por performances de cânticos e de elementos cristãos. Esses elementos podem ser vistos durante o cortejo religioso que dá início a festa do Çairé. Carregado por mulheres indígenas, o arco do Çairé13, um objeto que lembra um escudo português e que louva o Divino Espírito Santo, é um dos principais objetos da festividade. Outro momento ritual atrelado ao Çairé é o consumo do tarubá 14 que acontece durante o encerramento da festividade. Tanto o arco do Çairé, quanto o tarubá, são bidirecionais, sendo o resultado combinado de dois elementos (europeu católico e indígena) inseridos no festival.

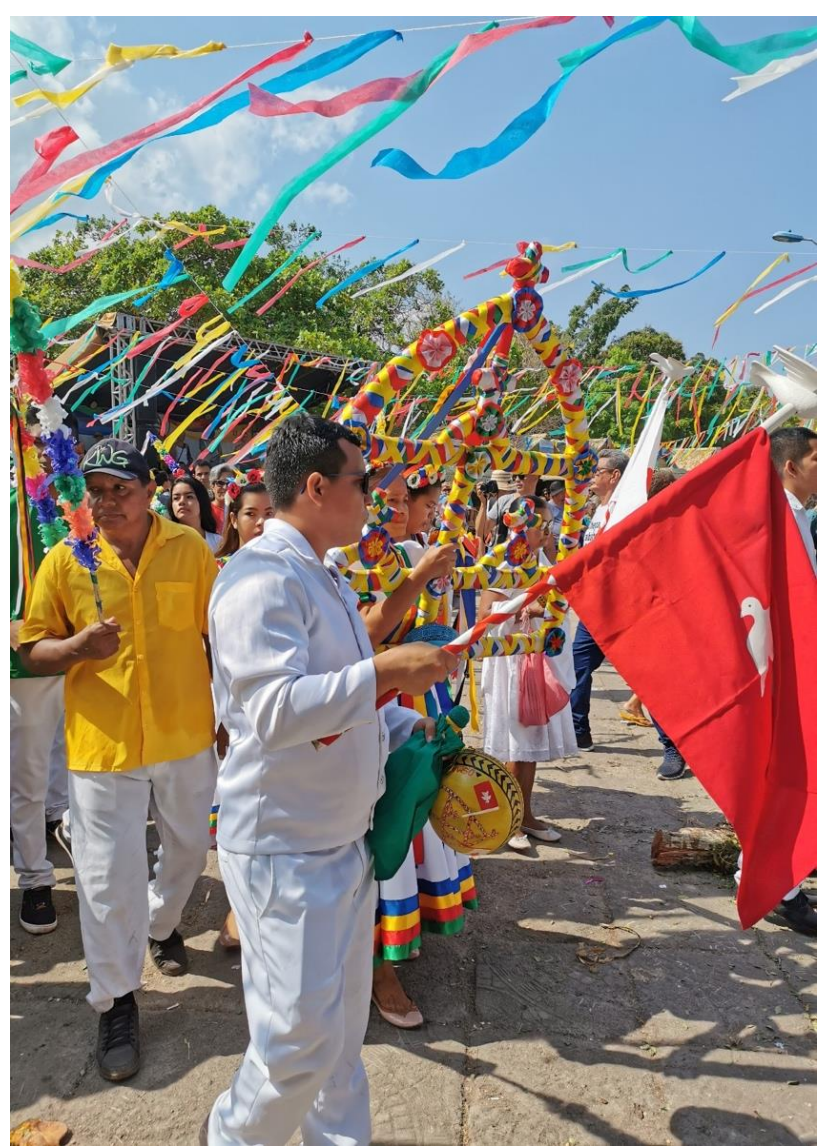

Figura 2. Festa religiosa: Cortejo religioso e o arco do Çairé. Foto: Igor Erick 


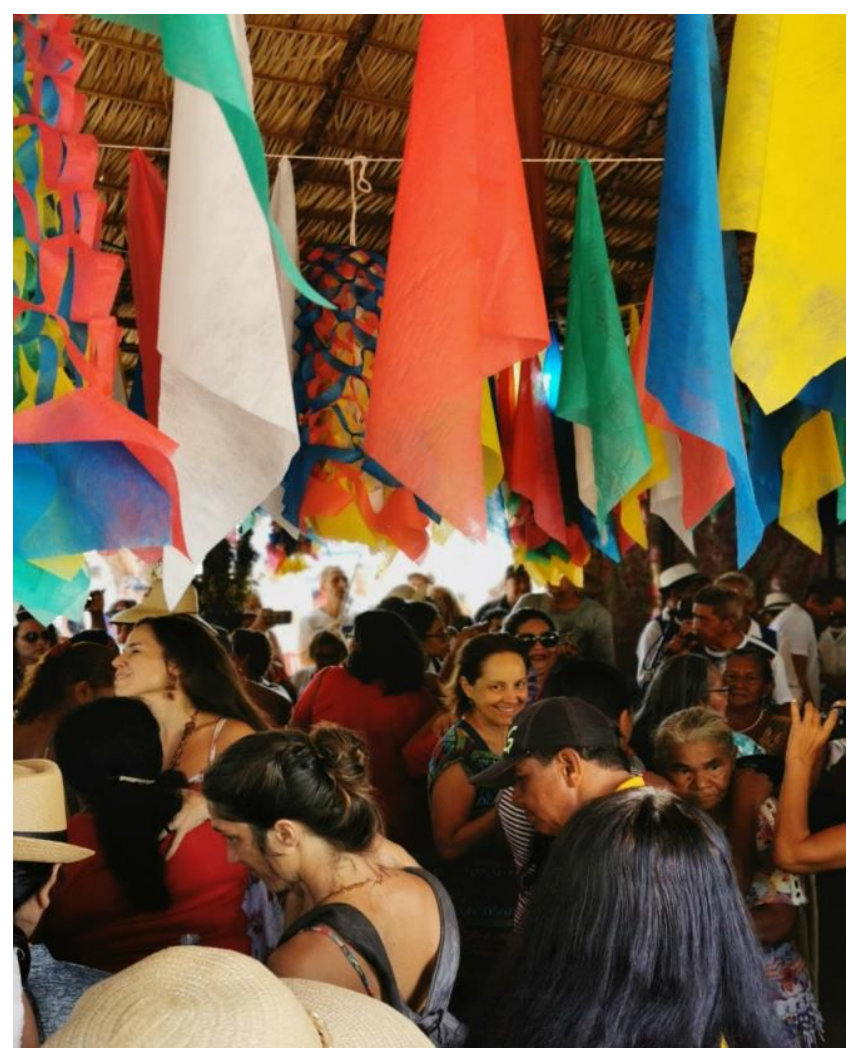

Figura 3. Turistas e nativos (indígenas e ribeirinhos) dançam após o consumo de tarubá. Foto: Igor Erick

Já a festa folclórica (o lado profano) acontece em diversas áreas pela Vila de Alter do Chão, principalmente no Çairódromo. Este último é um espaço voltado para as apresentações do festival, principalmente a disputa entre as duas agremiações que representam os botos (cor de rosa e tucuxi) na região. A introdução dos elementos locais, como as encantarias, os saberes e fazeres dos indígenas, ribeirinhos e caboclos na Amazônia, os rituais de pajelança, as performances do puxirum, a sedução entre o boto-homem e a cabocla Borari, entre outros enredos, mesclam-se às tecnologias apresentadas durante o espetáculo e aos shows de cantores nacionais. Os elementos inseridos transmitem a mensagem de que o festival folclórico é moderno e urbano: é um festival que delega estruturas atualizadas, que podem ser percebidas na fabricação de grandes carros alegóricos que comportam grandes guindaste para a sua locomoção, lâmpadas de LED e sistemas de fumaças que emergem entre as alegorias.

Os rituais religioso e profano criam pontes entre uma identidade local selecionada (indígena) e a cultura de entretenimento (festival folclórico) para serem transmitidas aos turistas e nativos presentes em Alter do Chão. Durante a realização da festa religiosa do Çairé é possível observar a manipulação de um passado colonial português com a introdução de elementos indígenas (indigenização), enquanto o profano apresenta um ritual que introduz elementos indígenas, ribeirinhos, caboclos e saberes/fazeres amazônidas em enredos que se misturam com tecnologias ${ }^{15}$. No entanto, há uma negação da presença indígena em Alter do Chão, principalmente nos debates sobre a demarcação das terras indígenas. Os atos de indeferimentos partem da maioria do setor empresarial (restaurantes e bares gourmets, hotéis e pousadas) e pelo setor da classe média santarena (em sua grande maioria, urbana e branca). Diante do conflito de glorificar uma identidade indígena durante os festivais e negá-la nas demandas de políticas locais,

${ }^{15}$ Tecnologias enquanto conjunto de técnicas, habilidade e métodos utilizados para a construção das alegorias. 
percebe-se que a introdução dos elementos e saberes indígenas no festejo podem ao mesmo tempo excluir os indígenas nas ações políticas e do outro lado, inseri-los em um contexto de entretenimento regional e internacional como um poderoso símbolo de identidade local (ALCALDE, 2009).

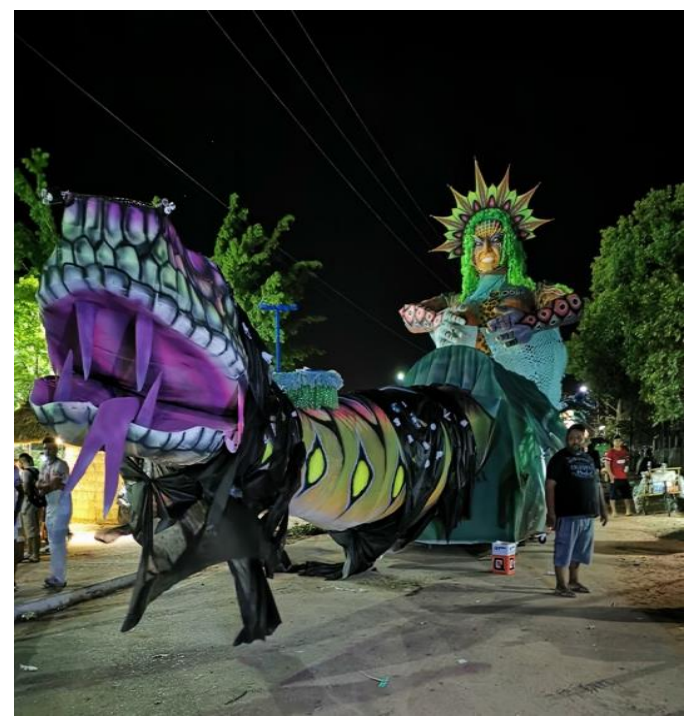

Figura 4. Alegoria que representa a cobra grande (encantaria) Foto: Igor Erick

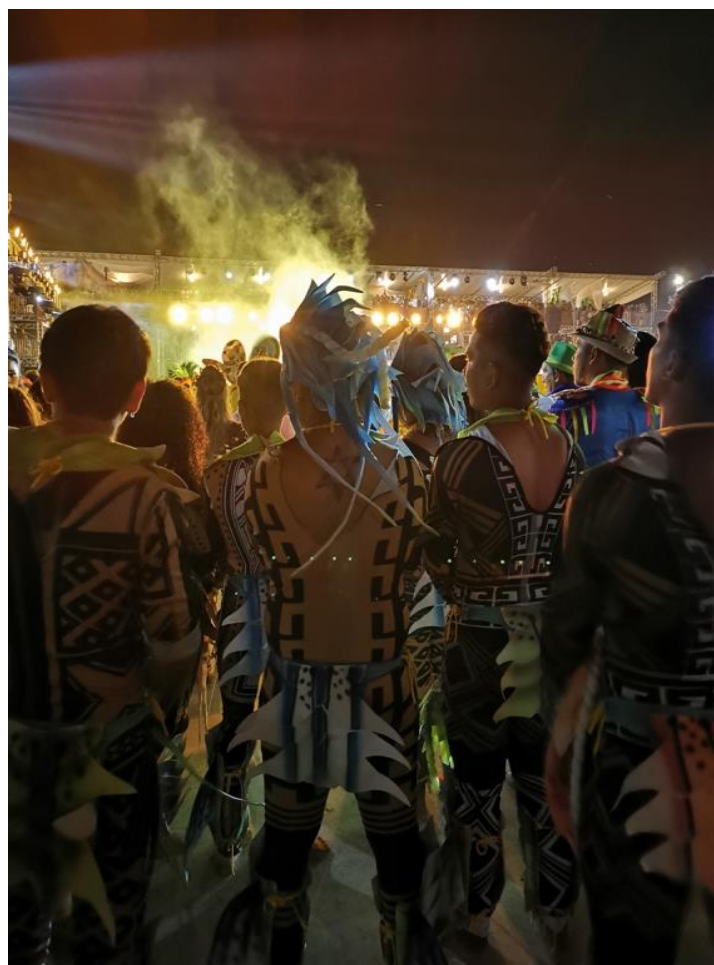

Figura 5. Dançarinos com grafismo corporal indígena em suas roupas. Apresentações das agremiações dos botos. Foto: Igor Erick 


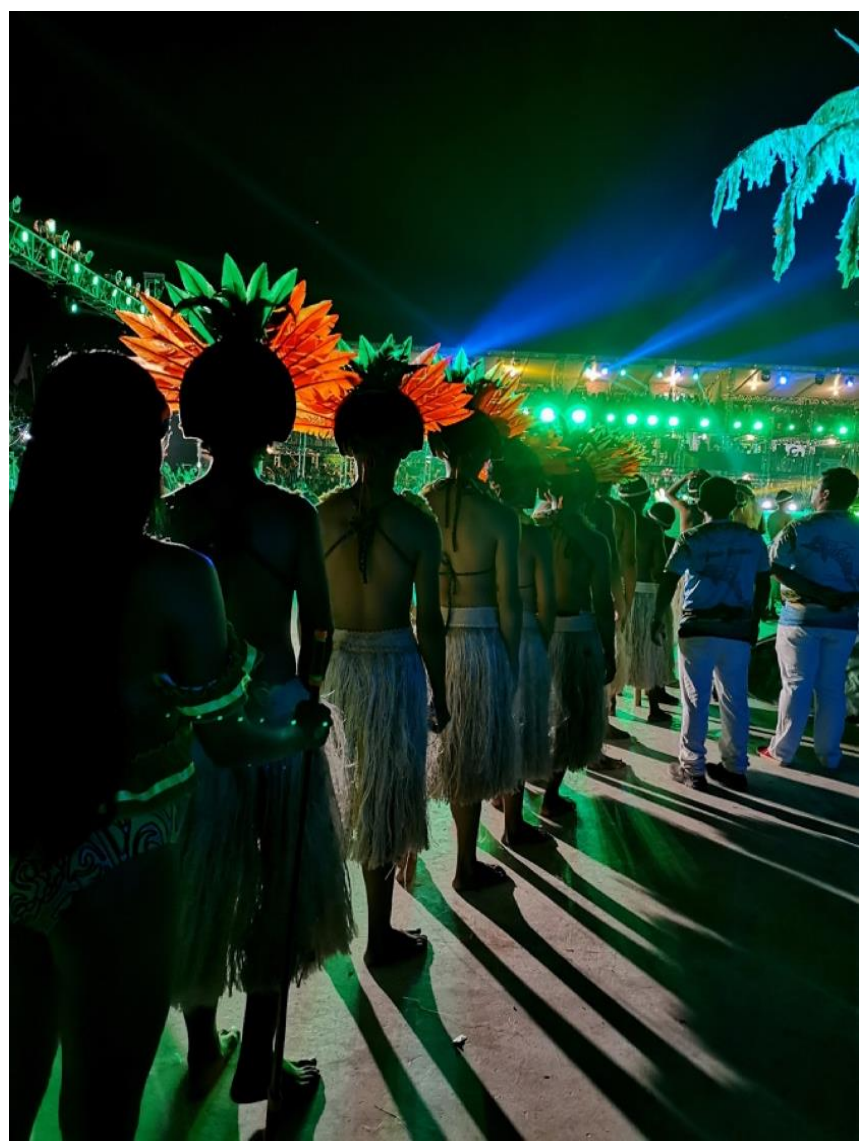

Figura 6. Indígenas Borari se preparando para adentrar no festival Çairé. Foto: Igor Erick.

\section{Os enredos sobre a encantaria do boto na Amazônia: sexualidade, desejo e libido}

Foi durante a realização do festival no Çairódromo que eu conheci Pedro Borari16, indígena, universitário, pajé da região e gay. É um dos principais ativistas da região e sua atuação política abrange tanto a Vila de Alter do Chão, quanto a região do Rios Tapajós e Amazonas. A sua circulação não se restringe ao seu movimento político, ela está presente nas universidades públicas, nos festejos, nas celebrações das festas de santos nas comunidades adjacentes, nos rituais afro-indígenas protagonizados por ele em dias de festas no terreiro e em suas viagens agendadas com a participação em eventos indígenas nacionais e internacionais.

Pedro Borari descreve a performance do boto-homem no festival durante a apresentação das agremiações. É um dos principais personagens da encantaria dessa região e uma das principais personalidades nas alegorias do Festival do Çairé. O seu enredo é caracterizado como sendo um homem encantador e sedutor, o seu encanto seduz e cega a cunhantã ou a cabocla mais bela da comunidade com a qual mantem um relacionamento. Hipnotizada pelo belo jovem rapaz e pela sua indumentária totalmente branca (chapéu, terno, calça e sapatos), a jovem moça já em transe não percebe o que está acontecendo e mantem um intercurso sexual com o boto-homem. Desse relacionamento, nasce uma criança que crescerá sem o pai na localidade e a ausência de uma figura paterna é parte da estrutura do mito do boto na Amazônia para explicar aos olhos externos o moti- 
vo de existir uma mãe solo na comunidade ribeirinha. O boto é habitante das cidades subaquáticas e, em dias de festas nas comunidades, transforma-se em homem para ir até o mundo humano. A sua aparência fora da água encanta aos olhos de quem o vê. Vestido de branco, elegante e sedutor, o boto-homem chama atenção de todas as mulheres que ali estiverem presentes, mas ele escolherá apenas uma moça para ter relação, e será a moça mais bela da comunidade.

O processo de metamorfose pelo qual o boto passa para ir até as comunidades ribeirinhas em dias de festa, é o uso que se faz da fauna aquática para a sua vestimenta "quando o encantamento se desfaz, seus chapéus são raias, seu dinheiro, algas e seus rostos, focinho de boto" (BELAUNDE, 2015: 552). Outro momento para que o boto apareça é em dia de resguardo mestrual, pois quando há quebra de restrição e a moça vai em direção ao rio, o sangue, ao entrar em contato com água, é sentido pelo boto, criando uma sensação de desejo que é sanada durante o ato do prazer sexual (BELAUNDE, 2015). Esses são alguns dos principais enredos da encantaria que se espalha por quase toda a Amazônia.

$\mathrm{O}$ enredo em que o boto-homem seduz um belo rapaz e um boto fêmea que seduz uma bela jovem não é visto pelos moradores da Amazônia e nem pela produção do festival do Çairé como sendo uma encantaria que pudesse fazer parte das realidades locais. A encantaria sobre o boto se prende ao mundo binário, homem e mulher (gênero/sexo) e a (re)produção do mito mantem a manutenção da sua estrutura referente ao binarismo de gênero/sexo. No entanto, nos estudos contemporâneos, há outros relatos sobre a presença do boto nas narrativas em que a sexualidade e o gênero são parâmetros de compreensão para as realidades sexuais cotidianas. Flávio Barros (2016) relata um caso sobre um pescador que manteve relações sexuais com uma "bota" (boto fêmea) durante a prática de pesca. $\mathrm{O}$ autor em sua pesquisa mostra que o pescador foi seduzido pela "bota" e que teria se relacionado sexualmente com ela em sua canoa. Domingues (2019), em sua análise sobre o cosmoerótico na Amazônia, apresenta o modo como os seus interlocutores interpretam os corpos dos botos. Segundo os seus informantes, os botos, por estarem muito próximos aos humanos, teriam aspectos físicos semelhantes aos humanos. Isto é, a vulva da bota ou, como é conhecida entre os seus interlocutores, "a buceta da bota", é similar à vulva da mulher, e, por isso, alguns pescadores, de acordo com suas análises, saem para pesca e quando passam semanas e até meses nos rios longe da terra firme, acabam transando com as botas capturadas durante as atividades de pesca. Outro aspecto ligado ao boto, é associado ao seu feromônio. Domingues (2019) mostra que a elaboração de produtos oriundos da biodiversidade da Amazônia, como banhos, óleos e perfumes é feita em sua grande maioria de partes de animais e plantas. O perfume do boto, que está ligado à libido, é o mais procurado entre homens e mulheres na seção de ervas e feitiços do Mercado do Ver-o-Peso, em Belém.

A imagem do boto, nesse sentido, está sendo construída por outros enredos e por outras realidades. Esses enredos são plurais e mostram o boto e/ou a bota em seus múltiplos usos no campo da diversidade sexual e gênero na Amazônia. $\mathrm{O}$ uso das encantarias nas realidades daqueles e daquelas que frequentam a Vila de Alter do Chão, é acionado e utilizado longe dos holofotes do festival, principalmente, nas praias de água doce que formam uma paisagem do desejo ${ }^{17}$.

${ }_{17}$ As paisagens dos desejos são espaços que conformam os desejos de ser, estar e sentir dos meus interlocutores com os espaços descritos durante a pesquisa de campo. São paisagens que regem um contexto histórico mais amplo do sentir das águas em seus corpos e ao seu uso para narrar as encantarias subaquáticas. 


\section{Para além do ser afetado: uma experiência atravessada pelo sensorial}

Ricardo, ribeirinho e morador de Alter do Chão, também narra as suas experiências em comunidades visitadas e durante as suas idas e vindas para Alter do Chão. As paisagens e as encantarias descritas pelo interlocutor são maneiras que ele encontrou para falar de sua sexualidade em interação com as águas dos rios. Além das praias e dos igarapés enquanto paisagens aquáticas, o interlocutor descreve os barracões das comunidades e o campo de futebol como espaços de encontros e namoros. Esses espaços, por fazerem parte das realidades das pessoas que habitam essas localidades, são considerados como um conjunto de paisagens inseridas nas experiências a seguir:

Autor. Na aldeia visitada por você, além do campo de futebol, tinha igarapé ou praia?

Ricardo. Tinha um igarapé. Já a praia ficava longe, pois a aldeia não ficava na várzea e sim, dentro da floresta, entrando a mata. E inclusive, fomos ao igarapé para tomarmos banho. A água desse igarapé era cristalina e bem gelada, tiramos muitas fotos.

Autor. Se você pudesse me descrever esse lugar, como você me descreveria?

Ricardo. É uma região de floresta, de mata fechada com grande árvores ao redor da aldeia. A água do igarapé muito cristalina, limpa e com pedras ao fundo. O lugar mais lindo que eu já vi. E ali, era um ótimo lugar para "fazer" um. (risos). Inclusive, nesse dia, foi um rapaz da aldeia lá com a gente tomar banho no igarapé, bem bonito inclusive. E quando ele ficava se banhando no igarapé, a gente comentava sobre o corpo dele, que era um corpo bonito, ficamos observando cada detalhe daquele corpo. Mas quando ele saia da água, a gente não conseguia ver volume nenhum, né? (risos). Inclusive, as outras gays ficaram se oferecendo para ele, mas eu não. Pois ele não me chamava atenção, por isso que eu não me aproximava. Mas o meu amigo se aproximou dele, efoi ele que puxou assunto com o rapaz.

Autor. Que tipo de assunto?

Ricardo. Era sobre uma questão do lugar, sobre os encantados de lá. E aproveitamos para perguntar se tinha alguma história que estava relacionado ao igarapé. $E$ o rapaz relatou que na própria comunidade existe um conto que fala sobre um cara que é uma cobra. É a história de um homem que virava uma cobra quando estava em contato com o igarapé, seria um tipo de encantado que protegia e protege aquele lugar. E geralmente ele só aparece nos dias de sexta feira pela parte da manhã quando a lua está cheia, isso de acordo com que o cara disse. Pois dar para ver a lua quando está de dia, né? Então, ele relatou que uma mulher acordou seis horas da manhã e foi até o igarapé para fazer alguns afazeres e quando estava próximo do igarapé, ela enxergou um homem entrando na água e sumiu, quando de repente, ela se aproximou e viu uma cobra no igarapé. Essa cobra, de acordo com o que ele disse, era gigante e assim que ela percebeu a mulher, a cobra foi embora.

Autor. Você teve alguma experiência durante o Çairé ou já teve outras experiências depois da festividade em Alter do Chão?

Ricardo. Eu já tive. Por exemplo, eu já fui para Alter para transar sob influência de outras pessoas, não que eu tive essa vontade de ir para a praia porque esquematizei desde o início um encontro, aconteceu ali. Esse meu amigo que me convidou, ele mora em Altamira e quando visita a cidade ele quer ir para Alter do Chão justamente para caçar. A estratégia que ele usa é ir para a ilha do amor, andar só de sunga curta de uma ponta da praia até outra só observando outros corpos e catando outros olhares para ele.

Autor. Você e seus amigos preferem a praia e o igarapé do que o motel? 
Autor. Por quê?

Ricardo. Acho que é o desejo. É muito fácil caçar nesses lugares. Por exemplo, como eu moro em frente a orla da cidade, eu só desço para caminha e consigo alguém. Quando acontece, nós vamos em direção a praia que fica em frente a cidade, e lá, acontece tudo. E outra coisa, lembra que você me perguntou sobre o campo de futebol na comunidade? Pois é, lembrei de uma coisa. Teve uma festividade em uma comunidade ribeirinha aqui perto de Santarém, sabe aquelas festas que tem torneio de futebol e depois festa no barracão com a banda da cidade? Pois é, depois e durante a festa todos vão para o campo, para atrás do barracão e até descem para a praia e o igarapé a noite, cansei de ver isso. Eu tenho a história do meu primo que até hoje mora na várzea.

Autor. Qual seria essa história?

Ricardo. Quando o meu primo teve a sua primeira relação sexual, foi com um outro primo. Ele conta que todas as tardes quando iam brincar ambos tinham curiosidades sobre o tamanho de seus pênis, e daí começavam a se masturbar um em frente do outro. $O$ meu primo disse que não era gay, que aquele momento era apenas um lance para conhecer partes de um corpo que era desconhecido para ambos. Já na adolescência, o meu primo disse que ele foram brincar em um barranco perto do roçado que fica próxima a praia e lá o cara começou a roçar o pênis dele na bunda do meu primo, depois teve penetração. Até hoje esse meu primo volta para a comunidade para manter os esquemas dele ativo, pois ele mora aqui na cidade de Santarém. Outro fato curioso sobre o meu primo, é que ele gostava de manter isso na lembrança, pois a mãe dele, minha tia, ainda mora lá. Veja só, é de lá que ele gosta mais e não daqui.

Autor. Voltando para a questão do teu primo, presta atenção no que ele disse. Percebe que a praia foi um dos primeiros lugares que ele teve a sua primeira transa? Nesse sentido, a praia me fez lembrar de algumas encantarias aquáticas, como o Boto por exemplo. Nesse sentido, você já teve alguma experiência com a encantaria além do homem cobra?

Ricardo. Sim! Teve um dia que eu e alguns amigos do nada decidimos ir para a vila de Alter do Chão. Mas antes de pegarmos a estrada, fomos comprar algumas bebidas para bebermos na areia da praia. Bom, chegando em Alter do Chão, éramos cinco pessoas e decidimos descer até a praia do Cajueiro e já estava de noite. Dentre esses cinco amigos, eu já estava flertando um cara que estava com a gente, já os outros três rapazes, tínhamos um casal e o cara que sobrou não resolveu ir com a gente. Chagando no Cajueiro, resolvemos fazer uma Piracaia e beber durante os intervalos de tempo entre o banho na água a noite e a bebida e comida. Depois da comida acabar, fomos os quatros para a água. O casal de amigos foi em direção a uma canoa que estava ancorada próximo da gente e eu e meu boy ficamos pouco distante deles. Eu lembro como se fosse hoje, pois na hora que eu estava nas preliminares com o meu ficante e o casal também, um boto cor de rosa apareceu do nada bem no meio de nós quatros, simplesmente o Boto deu aquela revoada na água e todos ficamos com medo, e nesse momento, corremos para a areia.

Autor. Como assim amigo? Um Boto apareceu entre vocês? Você sabe por quê?

Ricardo. Olha, não é com frequência que podemos ver Botos em Alter do Chão, mas eles aparecem no fim da tarde. Mas nesse dia, acho que era um boto gay (risos).

Autor. Boto gay?

Ricardo. Sim! Mas o que a gente conhece aqui, são sobre os Botos que seduzem as meninas em período fértil ou quando estão naquele dia (menstruadas). Eu também não entendi o porquê de um boto aparecer no meio de quatros homens gays. Creio que ele deva ter sentido o feromônio de todas ali ou foi o pitiú (risos). Mas que levamos um susto grande, levamos. Depois voltamos para a água, mas já não tinha mais clima e muito menos o boto apareceu de novo.

As experiências de Ricardo mostram que as paisagens são também frutos de desejos, relacionado a estar e sentir a água do igarapé. O barracão da comunidade e o campo de futebol estão inseridos nos espaços, onde esses espaços constituem e são constituídos enquanto paisagens: "A paisagem é uma série de locais 
nomeados, um conjunto de lugares relacionais conectados por trilhas, movimentos e narrativas 18" (TILLEY, 1994: 34). As paisagens do desejo são extensões que não somente fazem partes das realidades dos moradores e turistas, como também regem todo um contexto histórico do sentir as águas em seus corpos e do seu uso para narrar as encantarias aquáticas.

As paisagens (igarapés, praias, barracão da comunidade, campo de futebol da comunidade entre outros) se inserem nas realidades dos sujeitos enquanto espaços habitados, vivenciados e experienciados. Entendo as paisagens a partir de Tim Ingold (2000) e Chris Tilley (1994) enquanto mundos habitados, experienciados e vividos, mundos como são conhecidos por aqueles que nele habitam, fazem dele um registro duradouro. Os modos de habitar essas paisagens se dão através dos corpos humanos e não humanos, segundo os quais as pessoas constroem, e que surgem dentro de suas atividades de vida (INGOLD, 2000). Assim, as encantarias aquáticas (como a do boto) regem e transitam por uma rede de significados para os interlocutores explicarem os seus desejos, libidos, ereções, sexualidades e gêneros na Amazônia.

Além disso, as paisagens também podem ser descritas por meio da sensorialidade e por ser/estar no mundo. As representações dos corpos que estão inseridos nessas paisagens os fazem ser percebidos como sendo parte delas, isto é, os corpos criam as paisagens e as paisagens criam os corpos em um processo de agência e de interações com os sentidos e modos de ser e estar (Erick, 2020).

\section{Sexualidade e gênero a partir das relações entre humanos, não-humanos e coisas na Amazônia}

Diante de um vasto enredo sobre o boto-homem, nota-se que a cultura material atrelada à encantaria (em particular, o chapéu do boto-homem) também nos oferece outras percepções de como a indumentária pode ser pensada para além da ideia de interior e exterior como algo superficial e funcional, isto é, repudiar a abordagem semiótica das coisas. O problema é que ela faz das roupas meros servos, cuja tarefa é representar aquele que as utiliza (MILLER, 1954). O meu objetivo é refletir sobre os usos e desusos do chapéu do boto-homem entre os turistas e nativos, pensando a agentividade do chapéu (GELL, 2005), o encanto tecnológico (GELL, 2018) e seus aspectos mais sensuais (ALLERTON, 2007) durante as experiências observadas em Alter do Chão.

Penso o chapéu como um forte agente, um objeto que pode receber ou indexar relações de parentesco e as biografias de quem o usa e o produz (HOSKINS, 2008). Durante as minhas observações na Ilha do Amor, local de praias em frente à Vila, pude perceber como as pessoas, que interagiam umas com as outras e também com as paisagens, incorporavam as encantarias do boto-homem em suas atividades cotidianas, principalmente em suas conversas em rodas de amigos e amigas ou de familiares dentro do Rio Tapajós. O chapéu do boto era perceptível nas cabeças dos banhistas e sua relação com a encantaria era incorporada nas conversas. Eu ouço e observo um grupo com cinco pessoas na praia, mais precisamente dentro do rio. No grupo, há três mulheres e dois homens que esperavam outro participante, um amigo. Esse amigo está usando o chapéu do boto e vai em direção ao grupo. Ao ser percebido pelas mulheres que estão na água, o jovem rapaz que está se aproximando ouve "ui..ui...ui.. lá vem o boto", "cuidado, ele está usando o chapéu e vai lhe seduzir", "dança para gente boto-

18 Tradução livre do inglês: "A landscape is a series of named locales, a set of relational places linked by paths, movements and narratives” (TILLEY, 1994: 34). 
homem" e "olha o chapéu dele, que lindo, parece o boto".

Além do uso pelos banhistas, a indumentária pode ser consumida (enquanto mercadoria) para o uso pessoal. Podemos encontrar os chapéus nas barracas de palhas em frente a ilha e nas proximidades do Çairódromo. A venda também é feita pelos vendedores ambulantes nas areias das praias. São vendedores que circulam entre as praias oferecendo o produto junto com a biografia do botohomem: "Olha o chapéu do boto, quem vai querer seduzir o seu caboclo ou cabocla?” A sua produção é feita entre os artesãos locais com produtos nativos, como a palha das palmeiras de açaí (Euterpe oleracea). Os chapéus produzidos com esse material se aproximam do chapéu do boto visto nas barracas, nas apresentações do festival, nas artes plásticas, na literatura e nas narrativas locais. Esses últimos são produzidos muitas vezes em outras regiões, conhecidos como chapéu panamá. A sua cor é branca, mas comparada com este último, tem uma circunferência pequena em relação ao panamá.

O uso dos chapéus na Vila de Alter do Chão também pode ser percebida entre os moradores e até mesmo pode-se ouvir em conversas ou em situações jocosas na rua a sua associação com o boto-homem. Ao caminhar em direção ao espaço principal do festival, o Çairódromo, os vendedores nativos estão usando essas indumentárias, não para se proteger, porque a função seria essa, mas para mostrar que as metáforas espaciais e sexuais se encontram na superfície exterior do objeto. O chapéu pode ser interpretado como uma autoconstrução do eu, de um eu sedutor, de um eu prestes a seduzir a moça mais bela da festa. Portar o vestuário do boto não é usá-lo somente para se prevenir dos raios ultravioletas ou por se tratar de uma questão de estética, mas é usá-lo em um contexto de encantaria aquática presente nos dias de festivais. Esse traje faz parte de redes de conexões e emaranhados de relações em crescimento e movimento mais que humano presente nas realidades observadas, são relações que atravessam dois mundos (mundo dos humanos e não-humanos), são relações de negociações; os objetos moldam e são moldados diariamente em Alter do Chão por aqueles que os usam e por aqueles que os observam (LATOUR 2009; INGOLD, 2012).

O chapéu do boto-homem forma um sistema de informações que atravessam os corpos dos usuários e dos observadores. Durante as apresentações das disputas das duas agremiações dos botos no festival, pude observar as performances de sedução e encantamento encenadas pelo ator (boto) e a atriz (cabocla Borari) que nos ajudam a pensar como as indumentárias e o corpo nos guiam a um campo complexo de relações mais que humanas. Dentre as apresentações é importante destacar algumas, que é o caso dos quesitos de pontuação do concurso dos botos: sedução do boto, apresentador, cantador, rainha do Çairé, cabocla Borari, curandeiro, rainha do artesanato, boto homem encantador, boto animal evolução, rainha do Lago Verde, carimbó, organização do conjunto folclórico, alegorias, letra, música, ritual e torcida. Os quesitos destacados são itens encenados durante a realização do festival para os turistas e nativos presentes nas arquibancadas. Os quesitos sedução do boto, boto homem encantador, boto animal evolução e cabocla Borari são (re)produzidos nas interações entre nativos e turistas, turistas e nativos, turistas e turistas, nativos e nativos, turistas e paisagens, nativos e paisagens, paisagens e turistas e por fim, paisagens e nativos.

Pude observar as (re)produções dos itens em destaque na presença de Ricardo e Pedro durante um ensaio. Pedro, ao encenar a sedução do boto-homem junto com Ricardo (nesse enredo, Ricardo estava representando a cabocla Borari), utilizava um chapéu branco, uma camisa três-quartos de cor branca aberta, 
mostrando o seu peitoral e abdômen, além da calça também de coloração branca. Ricardo estava sem camisa e com um short. Foi assim que deram início à encenação da sedução do boto-homem. A performance aconteceu em uma praia do Lago Verde, a algumas centenas de metros do centro de Alter do Chão. A encenação do boto-homem é uma performance com bastante movimento do corpo, com auxílios das indumentárias: o corpo e o chapéu de Pedro, por exemplo, movem-se junto ao corpo de Ricardo, o chapéu camufla os olhares de Pedro fixados em Ricardo e escondem a sua "verdadeira" identidade animal, e, ao ser tocado com os dedos indicadores e polegar (movimento de pinça), o chapéu produz informações que podem ser interpretadas como gestos de cumprimentos e de sedução. Já a camisa, por outro lado, é usada para exibir o corpo bem definido (dentro dos padrões de beleza masculina) para aquele que recebe a sedução e, ao mesmo tempo, é utilizada como um instrumento para se conectar ao corpo receptor. A calça protege o corpo do sedutor, pois a sedução é feita na areia, além do aporte de proteção, indexando as substâncias corpóreas do seu usuário.

O boto-animal em evolução é um dos itens mais aguardados pelo público do espetáculo. Os botos cor de rosa e tucuxi são materializados em alegorias e manuseados por homens que se camuflam dentro da roupa de boto-animal. A importância dada ao boto-animal está justamente no aspecto que o animal dança com as caboclas e se desloca ao mundo dos humanos para interagir com as mulheres durante as apresentações. Depois desse processo, o boto-animal passa pela metamorfose e se desloca para a superfície em forma de um homem branco, loiro com os olhos claros ${ }^{19}$. As performances de sedução e metamorfose são re(produzidas) tanto por Ricardo, quanto por Pedro em momentos de lazer e encontros com amigos e amigas no Rio Tapajós. Nesses encontros, ambos performatizam tanto o boto-homem, quanto o boto-animal no rio. Este último é demonstrado nas relações jocosas na presença de homens com gritos de olha o boto! É uma brincadeira com a participação exclusiva de homens, por se tratar de mostrar parte das nádegas aos outros participantes do gênero masculino. Começa quando uma pessoa diz "lá vem o boto"; é nesse momento que alguns rapazes, ao imergir nas águas, apresentam as suas nádegas, imitando os movimentos do boto, quando o cetáceo vem à superfície para respirar e dá um salto antes de imergir novamente. Esse movimento é representado durante as apresentações do boto-animal no festival do Çairé.

Os enredos ${ }^{20}$ que envolvem as encantarias aquáticas, principalmente o botohomem, são narrativas que nos ajudam a refletir sobre a importância das indumentárias, principalmente o chapéu, nas relações mais que humanas (TSING, 2019). Mylene Mizrahi (2019) descreve como as roupas usadas por mulheres e homens nos bailes funks cariocas se configuram em estratégias de autoapresentação e da constituição de um sujeito criativo, permitindo-a adentrar em um mundo complexos de significados. Para a autora, as roupas usadas por homens nos bailes funk nos ajuda a pensar uma vinculação entre a maneira de dançar, o tipo de corpo valorizado e o estilo indumentário. Todos esses traços podem ser observados nas performances do boto-homem e no uso do chapéu, pois é importante que o usuário, além de portar o chapéu, apresente um tipo de corpo valorizado, um corpo em movimento. A fricção entre o corpo que seduz e o corpo re-

\footnotetext{
19 Ver Lima (2014) para uma interessante análise sobre o boto.

20 As imagens desta seção são do portal de notícias G1: https://g1.globo.com/pa/santarem-regiao/festival-dosaire/2017/noticia/boto-tucuxi-aposta-na-expressao-do-saire-para-seduzir-publico-e-jurados.ghtml.

https://g1.globo.com/pa/santarem-regiao/festival-do-saire/2018/noticia/2018/o9/23/ritual-indigena-do-boto-tucuxiclama-pela-preservacao-dos-rios-e-florestas.ghtml.http://g1.globo.com/pa/santarem-regiao/festival-do-saire/2017/. Acesso em: 10/04/202.
} 
ceptor nos demonstra as posições que ocupam um em relação ao outro. Sendo assim, o chapéu do boto e a performance da sedução envolvem necessariamente apreender o corpo a partir da relação que o corpo, o chapéu e a performance estabelecem entre si (MIZRAHI, 2019), já que "antes de qualquer coisa, a existência é corporal. Pela corporeidade, o homem faz do mundo a extensão de sua experiência” (LE BRETON, 2006: 7).

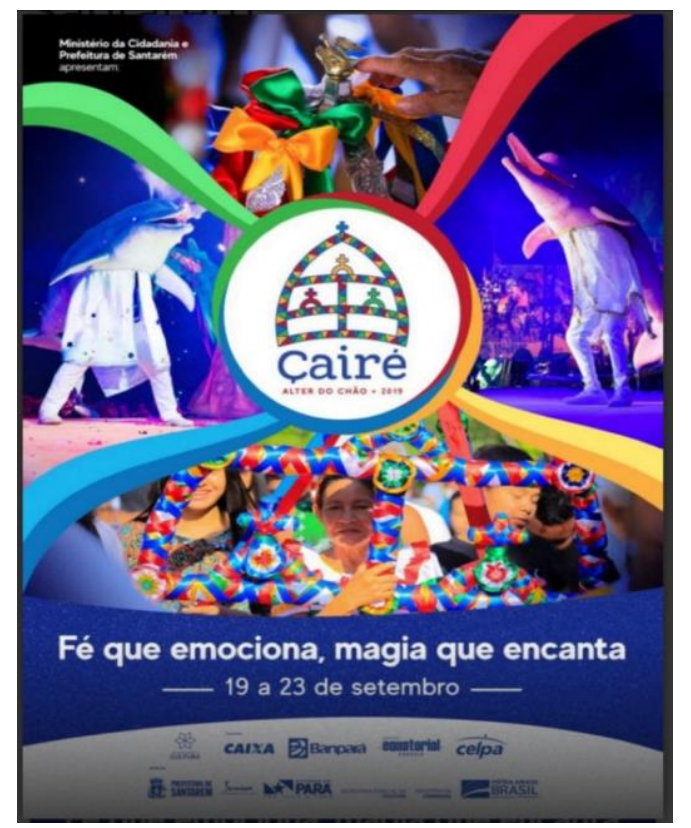

Figura 7. Elementos religioso e indígena. Foto: Reprodução

O boto-homem, o chapéu e o movimento observados durante a festividade e nas realidades das pessoas que frequentam a praia, assim como, no uso do chapéu no cotidiano dos nativos em suas experiências no âmbito do comércio e nas relações jocosas, mostram-nos agregados de delegações e atribuições de coisas humanas e não-humanas que emergem por meio da interação. É a partir do processo de inter-relações que o chapéu do boto pode agir, participar da vida social enquanto ator, ou seja, provocar eventos (LATOUR, 2012).

Outra possibilidade de interpretação sobre o uso do chapéu do boto e a importância do corpo nas experiências relatadas e nas descrições dos enredos sobre a encantaria, é introduzi-los na perspectiva das metáforas de pele. Catherine Allerton (2007), descreve a vida social e "secreta" dos sarongs usados por homens e mulheres na Ilha de Flores, na Indonésia, como "super-peles”. Segundo a autora, os sarongs possuem capacidades de proteger, embrulhar, esconder, absorver substâncias e intenções, oferecem conforto, transmitem mensagem sociais e emocionais entre outros... proporcionando uma gama de possibilidade de conexões com os variados destinos e projetos de vidas individuais. As indumentárias utilizadas pelo boto-homem, turistas e nativos podem ser consideradas como um tipo de super-pele. O chapéu usado nas encenações do festival e no cotidiano das pessoas passam por aspectos sensoriais e sensuais. Além desses aspectos, esse objeto e as demais indumentárias utilizadas pelo boto e outros usuários também são responsáveis pela manutenção do tráfego entre os dois mundos, o mundo dos encantados e o mundo dos humanos. Além disso, o chapéu enquanto vestuário é companheiro íntimo dos seus usuários, a sua ligação com a intimidade está atrelada ao corpo, as emoções (desejo) e as substâncias 
de seus próprios usufrutuários, assim como, são apreendidos como uma extensão do corpo do seu portador.

A maneira que o chapéu do boto é ordenado no mundo e o modo como os objeto nos ordenam são importantes para assinalar os fonemas presentes nos dizeres "olha o chapéu do boto" ou "lá vem o boto" do grupo de amigos no Rio Tapajós citado mais acima. São sons produzidos que ocupam uma posição de destaque entre o usuário e a encantaria (boto-homem). Já as indumentárias apresentadas delegam agências entre seus usuários e observadores, o chapéu do boto por exemplo, pode-se dizer que têm biografias, as pessoas o usam porque investem seus aspectos de suas próprias biografias no chapéu, assim como, os chapéus investem nas pessoas seus aspectos cosmológicos na biografia do seu usuário, ou seja, eles são investidos com personalidades e podem ter um impacto nas relações em que estão inseridos (HOSKINS, 2008).

Outro ponto que pretendo destacar sobre chapéu do boto é o processo de objetificação, encanto, reprodutor cosmológico e agentividade (MILLER, 1954; GELL, 2005; BARRETO e OLIVEIRA, 2016; GELL, 2108). A objetificação do chapéu do boto está inserida nas tentativas dos interlocutores e demais personagens desenvolverem formas pelas quais constroem ou passam a entender a si próprio e o mundo a partir do uso do objeto e da encantaria. Assim, a objetificação dará forma à ideia de que o chapéu nos faz como parte do processo pelo qual os fazemos: "[...] externalizar-se como cultura e se reconhecer naquilo que foi criado. Eles objetificam” (MILLER, 1954: 99).

Já o encanto está presente no ato do uso, pois o chapéu carrega consigo a magia que transcende nossa ligação com a vida material e, nesse sentido, a encantaria é melhor expressada tanto pelo uso das indumentárias, quanto pelas performances corporais. O chapéu do boto não transmite seu poder de fascinação na tecnologia, e sim, na história que transmite. $O$ encanto se expressa por meio da socialização dos seus usuários e observadores em uma rede de intencionalidade. Portar um chapéu que é usado pelo boto-homem, é transmitir ao seu observador ou observadora uma fascinação que o admira e enfraquecer o domínio de si. O poder ou a magia do chapéu do boto reside nos processos simbólicos e na cativação, este último produz um efeito de sermos incapazes de entender como as indumentárias do boto-homem surgem no mundo dos humanos e como os humanos as utilizam para re(produzir) as suas biografias, isto é, o poder é especificamente visual (GELL, 2005).

Por fim, o chapéu pode ser pensado como um objeto responsável pela reprodução cosmológica e agentividade nos/dos seus usuários. Em certos momentos as pessoas podem assumir atributos dos seus objetos, e ao mesmo tempo, os objetos podem assumir atributos do seu portador. Além do mais, o chapéu do boto pode receber um gênero, nome, história e função ritual. Para Janet Hoskins (2008) os objetos não assumem somente uma série de identidades diferentes como por exemplo, valor ancestral ou mercadoria, os objetos podem interagir com aqueles que o observa, usam e possuem. Em relação a sua morfologia está associada a arraia (Batoidea) não replica só as formas ou a sua aparência externa, mas a capacidade dos seres ancestrais ou míticos (a encantaria do homem-boto) de agirem sobre o mundo. Fazer o uso do chapéu do boto, por exemplo, seja na apresentação do festival ou na praia é, portanto, reatualizar as encantarias, os conhecimentos e as cosmologias. O chapéu e seus atributos podem ser apreendidos como sendo partes de mundos e corpos múltiplos que demarcam territórios ancestrais encontrados em um universo ameríndio (BARRETO e OLIVEIRA, 2016). 


\section{Considerações finais}

Com efeito, a cultura material, principalmente as indumentárias presentes nas atualizações das encantarias amazônicas, nos revela um universo complexo de sistema ou redes de significados simbólicos, assim como outras formas e regimes de percepções do mundo (ou seja, ser/estar no mundo) que vão além de representações, signos ou símbolos. Pensar esses trajes e relacioná-los à sexualidade e ao na Amazônia por meio da encantaria do boto-homem é um trabalho essencial. A cultura material está presente em nossas experiências, transmitenos formas de habitar esse mundo, age, cria e produz intencionalidades nas existências das pessoas e criam linhas de devir. Assim, o vestuário do botohomem não é apenas uma roupa silenciosa sem vida, mas nos mostra uma rede de significados importantes. Os exemplos citados no texto nos guiam no interior dessas redes ou teias de significados, são formas para indicar como as pessoas ordenam ou organizam o mundo por meio da materialidade, da paisagem e da encantaria que atravessam a sexualidade e o gênero na Amazônia.

Em suma, é importante propor outros modos de pensar o mundo, um mundo de múltiplas naturezas e corpos, um mundo em que a presa (a cabocla Borari e os banhistas) e o predador (boto-homem e o chapéu do boto) assumem, enquanto agentes transmissores e receptores, relações de comunicação e, também, consciência, intencionalidade e agência. Nesse sentido, não é a minha intenção pensar essas relações enquanto "ideologia venatória", mas em um processo presente em um mundo transformacional pelas ontologias amazônicas (VIVEIROS DE CASTRO, 1996), que nos mostram outras possibilidades de refletir sobre os estudos de sexualidade e gênero no Brasil. Assim, tanto o boto-homem, quanto o chapéu do boto, são concebidos como pessoas e objetos dotados de uma alma e/ou agência que lhes aferem atributos idênticos aos dos humanos (DESCOLA, 1997), dentre eles, desejo, sexualidade, ontologias e formas de pensar o mundo.

Recebido em 19 de fevereiro de 2021. Aprovado em 13 de abril de 2021.

\section{Referências}

ALCALDE, Cristina. Between Incas and Indians Inca Kola and the construction of a Peruvian-global modernity. Journal of Consumer Culture, 9 (1): 9-31, 2009. ALBERTI, Benjamin. Archaeologies of Ontology. Annual Review of Anthropology, 45: 163-79, 2016.

ALLERTON, Catherine. The secret life of sarongs: Manggarai textiles as superskins. Journal of Material Culture, 12 (1): 22-46, 2007.

ALVES, Daiana Travassos. Ocupação indígena na foz do rio Tapajós (326o- 
96oAP): estudo do sítio Porto de Santarém, baixo Amazonas. Dissertação de mestrado, PPGA-UFPA, 2012.

BARRETO, Cristiana e OLIVEIRA, Erêndira. Para Além de Potes e Panelas: Cerâmica e Ritual na Amazônia Antiga. Habitus, 14 (1): 51-72, 2016.

BARROS, Flávio. "E a bota encantou o homem que dormia na rede". In: SOUTO, F. J. B. et alii. (orgs.). Quando pensa que não... contos, causos e crônicas em Etnoecologia. v. 2. Feira de Santana: Z-Arte Editora, 2016. pp. 143-145.

BELAUNDE, Luisa Elvira. Resguardo e sexualidade(s): uma antropologia simétrica das sexualidades amazônicas em transformação. Cadernos de Campo, 24: 538-564, 2015.

BELAUNDE, Luisa Elvira. O estudo da sexualidade na etnologia. Cadernos de campo, 24: 399-411, 2015.

BRAH, Avtar. Diferença, Diversidade, Diferenciação. Cadernos Pagu, 26: 329376, 2006,

CARVALHO, Luciana Gonçalves de. Festa do Çairé de Alter do Chão. Santarém: UFOPA, 2016.

DESCOLA, Philippe. "Ecologia e Cosmologia”. In: EDNA, Castro e FLORENCE, Pinton (orgs.). Faces do Trópico Úmido: conceitos e questões sobre o desenvolvimento e meio ambiente. Belém: Editora CEJUP, 1997.

DOMINGUES, Bruno Rodrigues Carvalho. Entre tradição, desejo e poder: uma Amazônia cosmoerótica. Trabalho de Conclusão de Curso - Faculdade de Ciências Sociais, Instituto de Filosofia e Ciências Humanas, Universidade Federal do Pará, 2019.

ERICK, Igor. (Re)pensando a diversidade sexual e de gênero fora do(s) grande(s) centro(s). Novos Debates, 5 (1-2): 116-127, 2019.

ERICK, Igor. Entre corpos, sensações e paisagens: reflexões sobre a diversidade sexual e de gênero no interior da Amazônia. Dissertação de mestrado - Programa de Pós-Graduação em Antropologia, UFPA, 2020.

GELL, Alfred. "A tecnologia do encanto e o encanto da tecnologia". Concinnitas, 8 (1): 42-63, 2005.

GELL, Alfred. Arte e Agência. Trad. Jamille Pinheiro Dias. São Paulo: UBU Editora, 2018.

GOLDMAN, Márcio. Alteridade e experiência: antropologia e teoria etnográfica. Etnográfica, 10 (1): 159-173, 2006.

HEIDEGGER, Martin. Ser e Tempo (parte I). Petrópolis: Vozes, 1995.

HOSKINS, Janet. “Agency, biography and objects”. In: TILLEY, Christopher; et alii (eds.). Handbook of Material Culture. New York: Sage, 2008. pp.74-84.

INGOLD, Tim. The Perception of the Environment: essays on livelihood, dwelling and skill. London: Routledge, 2000.

INGOLD, Tim. Trazendo as coisas de volta à vida: emaranhados criativos num mundo de materiais. Horizontes Antropológicos, 18 (37): 25-44, 2012.

LATOUR, Bruno. Jamais fomos modernos: ensaio de antropologia simétrica.

São Paulo: Editora 34, 1994. 
LATOUR, Bruno. "Where are the Missing Masses? The Sociology of a Few Mundane Artifacts.” In: CANDLIN, Fiona; GUINS, Raiford (eds.). The Object Reader. London: Routledge, 2009. pp. 229-254.

LATOUR, Bruno. Reagregando o Social: uma introdução à Teoria do AtorRede. Trad. Gilson César Cardoso de Sousa. Salvador: Edufba, Bauru: Edusc, 2012.

LE BRETON, David. A sociologia do corpo. Tradução de Sonia M.S.Fuhrman, Petrópolis: Vozes, 2ed, 2006.

LIMA, Deborah de Magalhães. O homem branco e o boto: o Encontro colonial em narrativas de encantamento e transformação (Médio rio Solimões, Amazonas). Teoria e Sociedade. Número especial: Antropologia e Arqueologia, hoje, 2014 .

MAUÉS, Raymundo H. A ilha encantada: medicina e xamanismo. Belém: NAEA, 1990.

MILLER, Daniel. Trecos, troços e coisas: estudos antropológicos sobre a cultura material. trad. Renato Aguiar. Rio de Janeiro: Zahar, 1954.

MIZRAHI, Mylene. O funk, a roupa e o corpo: caminhos para uma abordagem antropológica da moda. Cadernos de Arte e Antropologia, 8 (1): 105-121, 2019.

SIMMEL, Georg. Questões fundamentais da sociologia: indivíduo e sociedade. Rio de Janeiro: Zahar, 2006. pp. 59-82.

SCHUTZ, Alfrad. Fenomenologia e relações sociais. Rio de Janeiro: Zahar, 1970.

TILLEY, Chris. "Space, Place, Landscape and Perception: phenomenological perspectives". In: A Phenomenology of Landscape: places, paths and monuments. Oxford: Berg, 1994. pp. 7-34.

TSING, Anna Lowenhaupt. Viver nas ruínas: paisagens multiespécies no antropoceno. Ed. Thiago Mota Cardoso, Rafael Victorino Devos. Brasília: IEB Mil Folhas, 2019.

VIVEIROS DE CASTRO, Eduardo. Os pronomes cosmológicos e o perspectivismo ameríndio. Mana, 2 (2): 144-196, 1996. 